\title{
Botany
}

\section{Uncoupling effect of lipid peroxidation in spinach thylakoids exposed to peroxyl radicals generated by 2,2'-azobis (2- amidinopropane) dihydrochloride}

\begin{tabular}{|c|c|}
\hline Journal: & Botany \\
\hline Manuscript ID & cjb-2021-0032.R1 \\
\hline Manuscript Type: & Article \\
\hline $\begin{array}{r}\text { Date Submitted by the } \\
\text { Author: }\end{array}$ & 15-Jun-2021 \\
\hline Complete List of Authors: & $\begin{array}{l}\text { La Haye Yergeau, Olivier; Université du Québec à Trois-Rivières, } \\
\text { Département des sciences de l'environnement } \\
\text { Samson, Guy; Université du Québec à Trois-Rivières, Département des } \\
\text { sciences de l'environnement }\end{array}$ \\
\hline Keyword: & $\begin{array}{l}\text { AAPH, ATP synthesis, oxidative stress, photosynthesis, reactive oxygen } \\
\text { species }\end{array}$ \\
\hline $\begin{array}{r}\text { Is the invited manuscript for } \\
\text { consideration in a Special } \\
\text { Issue? : }\end{array}$ & Not applicable (regular submission) \\
\hline
\end{tabular}

\section{SCHOLARONE ${ }^{m}$ Manuscripts}




\section{Uncoupling effect of lipid peroxidation in spinach thylakoids exposed to peroxyl radicals generated by $2,2^{\prime}$-azobis (2- amidinopropane) dihydrochloride}

Olivier La Haye Yergeau and Guy Samson*

Groupe de recherche en biologie végétale, Département des sciences de l'environnement, Université du Québec à Trois-Rivières, C.P. 500 Trois-Rivières QC Canada G9A 5H7

* Corresponding author: Guy.Samson@uqtr.ca; Phone: 819-376-5011, ext. 3374;

Fax: 819-376-5084 


\begin{abstract}
In this study, we characterized how lipid peroxidation alters the functionality of spinach thylakoids exposed to peroxyl radicals generated by the azo compound 2,2-azobis(2-amidinopropane) dihydrochloride (AAPH). Incubation of thylakoids in presence of different concentrations ( 0 to 200 $\mathrm{mM})$ of AAPH inhibited the formation of $\Delta \mathrm{pH}\left(\mathrm{IC}_{50} \approx 1.5 \mathrm{mM}\right)$ estimated by the quenching of 9aminoacridine fluorescence (Q9-AA). The Q9-AA inhibition was correlated $\left(\mathrm{R}^{2}=0.98\right)$ to the extent of lipid peroxidation determined by the accumulation of thiobarbituric acid reactive substances (TBARS). Much higher AAPH concentrations were required to inhibit the maximum (Fv/Fm) and effective $\left(\Delta \mathrm{F} / \mathrm{Fm}\right.$ ') photochemical efficiencies of photosystem II $\left(\mathrm{IC}_{50} \approx 120 \mathrm{mM}\right.$ and $50 \mathrm{mM}$ respectively), indicating that moderate lipid peroxidation caused the uncoupling of spinach thylakoids. This was confirmed by the $62 \%$ stimulation of the $\mathrm{O}_{2}$ uptake rates measured without the artificial uncoupler $\mathrm{NH}_{4} \mathrm{Cl}$ when the AAPH concentrations increased from 0 to at $20 \mathrm{mM}$, reaching similar values to the rates measured in presence of $\mathrm{NH}_{4} \mathrm{Cl}$. Above $20 \mathrm{mM} \mathrm{AAPH}$, the $\mathrm{O}_{2}$ uptake rates measured with and without $\mathrm{NH}_{4} \mathrm{Cl}$ declined similarly to the decrease of $\Delta \mathrm{F} / \mathrm{Fm}$ '. These results suggest that the increased $\mathrm{H}^{+}$-leakiness of thylakoid membranes could be one of the primary effects of oxidative stress.
\end{abstract}

\title{
Key words
}

9-aminoacridine; AAPH; ATP synthesis; oxidative stress; chlorophyll fluorescence;

malondialdehyde; non-photochemical quenching; photosynthesis; photoinhibition; reactive oxygen species.

\author{
Abbreviations: \\ AAPH: 2,2'-azobis (2-amidinopropane) dihydrochloride \\ Fv/Fm: maximum photochemical efficiency of photosystem II \\ $\Delta \mathrm{F} / \mathrm{Fm}$ ': effective photochemical efficiency of photosystem II \\ MDA: malondialdehyde
}

Q9-AA: quenching of 9-aminoacridine fluorescence

PSII: photosystem II

ROS: reactive oxygen species

TBARS: thiobarbituric acid reactive substances 


\section{Introduction}

Light absorption in the chloroplasts inevitably leads to the production of reactive oxygen species (ROS) due to pigment excitation and electron transfer reactions occurring in presence of high $\mathrm{O}_{2}$ concentrations (Dietz et al. 2016; Noctor et al. 2018). These ROS can be useful for the plants by safely dissipating energy, thanks to efficient ROS scavenging systems (Noctor and Foyer 1998), and also, by acting as signal molecules involved in metabolic adjustments and plant acclimation to the ambient conditions (Mittler 2002; Apel and Hirt 2004; Foyer et al. 2017). However, a diversity of environmental stresses can exacerbate the effect of high light intensities by increasing the production of ROS to a level that overwhelms the capacity of the scavenging systems. The excess of ROS can affect plant performance by causing oxidative damages to vital cellular components such membranes, enzymes, and genes (Dietz et al. 2016).

Excessive ROS production in the chloroplast results from a cascade of reactions, starting from limitations of the $\mathrm{CO}_{2}$ assimilation relative to the reducing power generated by the light reactions. The resulting depletion of the terminal electron acceptor $\mathrm{NADP}^{+}$promotes the Mehler reaction at the photosystem I (PSI) acceptor side, where an electron is transferred to $\mathrm{O}_{2}$ to form the anion superoxide $\mathrm{O}_{2}^{-}$(Asada 2006). This ROS normally dismutates to $\mathrm{H}_{2} \mathrm{O}_{2}$, less toxic but which can be transformed via Fenton reaction to the highly toxic hydroxyl radical $(\mathrm{HO} \bullet)$. Electron leakage to $\mathrm{O}_{2}$ can also occur at the acceptor side of photosystem II (PSII), where the resulting $\mathrm{O}_{2}{ }^{-}$dismutates to $\mathrm{H}_{2} \mathrm{O}_{2}$, which is then reduced by the non-heme iron to $\mathrm{HO} \bullet$ (Pospíšil 2016). Limitation of $\mathrm{CO}_{2}$ assimilation relative to the light reactions also causes the slowdowns of pigment de-excitation and electron transfer, thereby increasing the risk of singlet ${ }^{1} \mathrm{O}_{2}$ formation in PSII when $\mathrm{O}_{2}$ interacts with triplet chlorophylls formed either in the antenna directly from excited singlet chlorophyll, or in the reaction center after charge recombination between $\mathrm{Pheo}^{-}$and $\mathrm{P} 680^{+}$(Dietz et al. 2016). Finally, slow electron transfer on the PSII donor side increases the lifetime of TyrZ $\cdot$ and P680 ${ }^{+}$. These two strong oxidants can extract electrons from nearby lipids and proteins, creating unstable lipid alkyl radical $(\mathrm{L} \cdot)$ and protein $(\mathrm{P} \cdot$ ) radicals (Pathak et al. 2017).

One of the primary targets of the chloroplastic ROS is the thylakoid membrane due to its highly polyunsaturated fatty acids prone to lipid peroxidation (Halliwell 1987). HO-, the main initiator of lipid peroxidation, can extract a $\mathrm{H}$ atom from a methylene group $\left(-\mathrm{CH}_{2}-\right)$ of a fatty acid to produce an alkyl radical $\mathrm{L} \bullet$, which reacts rapidly with $\mathrm{O}_{2}$ to create a lipid peroxyl radical (LOO•) (Yalcinkaya et al. 2019). These radicals were detected for example in thylakoids from plants exposed to atmospheric ozone (Gupta et al. 1991) or UV-B (Hideg and Vass 1996). Then, LOO• can extract a $\mathrm{H}$ atom from an adjacent $\mathrm{LH}$, creating another $\mathrm{L} \bullet$. This chain of reactions continues until it is terminated with the reduction of $\mathrm{LOO} \cdot$ to hydroperoxides $(\mathrm{LOOH})$ by $\alpha$-tocopherol or other antioxidants (Munné-Bosch 2005). Besides $\mathrm{HO} \cdot,{ }^{1} \mathrm{O}_{2}$ can also create a $\mathrm{LOOH}$ by adding an $\mathrm{O}_{2}$ to a $\mathrm{C}$ atom adjacent to a double bond of polyunsaturated fatty acid. $\mathrm{LOOH}$ can further react to form secondary products (reactive carbonyl species) such as malondialdehyde (MDA), a wellknown marker of lipid peroxidation (Pospíšil and Yamamoto 2017; Yalcinkaya et al. 2019).

Lipid peroxidation and its secondary products can affect the functions of the thylakoids firstly by damaging the proteins involved in the photosynthetic electron transport, notably those in the PSII reaction center (D1), in the light-harvesting complex LHCII, and the peripheral proteins on the PSII donor side (Yamauchi et al. 2008; Pospíšil and Yamamoto 2017). Dysfunction of 
oxidized proteins can result from subtle conformational changes, or from more extensive damages such as cleavage and aggregation (Pospíšil and Yamamoto 2017). Concomitant lipid peroxidation and inhibition of photosynthetic electron transport are commonly observed in thylakoids from plants exposed to diverse stresses such as cadmium (Prasad and Zeeshan 2005), drought (Zlobin et al. 2019), Mg deficiency (Farhat et al. 2015), and waterlogging (Yan et al. 2018).

Besides electron transport, ATP synthesis is the other fundamental function of the thylakoids that is susceptible to lipid peroxidation. Inhibitions of ATP synthesis have also been observed in plants exposed to a variety of physiological and environmental stresses (Ortiz-Lopez et al. 1991; Tezara et al. 1999; Lawlor and Cornic 2002; Allakhverdiev et al. 2008; Ma et al. 2016). However, only few studies reported lipid peroxidation (MDA accumulation) concurrently to the inhibition of ATP synthesis during oxidative stresses induced by anoxia/re-aeration (Rawyler et al. 2002), salt (Zheng et al. 2009; Yousuf et al. 2017) and $\mathrm{H}_{2} \mathrm{O}_{2}$ (Dubovskaya et al. 2007). Furthermore, none of these studies identified the direct cause of ATP synthesis inhibition, which could be the inactivation of the F-ATPase, the inhibition of the photosynthetic electron transport, or the inhibition of the formation of $\mathrm{pH}$ gradient $(\Delta \mathrm{pH})$ due to an increase of membrane leakiness to $\mathrm{H}^{+}$. In that latter case, a loss of membrane integrity due to lipid peroxidation would cause the uncoupling of the thylakoids, i.e. photosynthetic electron transport functioning independently of the activity of ATP synthase. In this condition, $\mathrm{H}^{+}$-leaky thylakoid membranes prevent the acidification of the lumen, thereby inhibiting ATP synthesis while allowing electron transport to proceed without the restriction of the plastoquinol oxidation in the cytochrome $b_{6} f$ imposed by the low luminal $\mathrm{pH}$ (Dean and Miskiewicz 2003). Besides the inhibition of ATP synthesis, the physiological consequences of this uncoupling would be multiple: the collapse of non-photochemical quenching $\mathrm{qN}$, leading to the overreduction of the electron transport chain, thereby increasing the rates of ROS formation and photoinhibition.

A possible uncoupling effect of lipid peroxidation has not been yet demonstrated in thylakoids. Despite that chloroplasts and mitochondria largely differ in terms of electrons carriers and lipid composition (Schwertner and Biale 1973), such uncoupling in thylakoids is suggested by observations of simultaneous lipid peroxidation and uncoupling in liver mitochondria isolated from mice that received intraperitoneal injection of a peroxyl radical initiator, 2,2'-azobis-(2amidinopropane) dihydrochloride (AAPH) (Kanno et al. 1994). This water-soluble azo compound is widely used as a model reagent to mimic oxidative stress due to its ability to generate peroxyl radicals at a constant rate at physiological temperatures (Niki 1990). It is used to induce oxidative stress in various in vivo and in vitro biological systems, such as rat lungs (Gomes et al. 2016), zebrafishes (Wang et al. 2018), chicken embryos (He et al. 2013), human erythrocytes (Zou et al. 2001) and to induce peroxidation of low-density lipoproteins (Yoshida et al. 2004) and of phosphatidylcholine liposomes (Mendez-Sanchez et al. 2009). It is also used in ORAC (oxygen radical absorbance capacity) assays to evaluate the antioxidant capacity of different compounds to protect target molecules (e.g., phycoerythrine, fluorescine, pyrogallol red) against peroxyl radicals (Prior et al. 2005). In contrast to these numerous examples, the effects of AAPH on plants are rare. For example, AAPH stimulated the ROS defense system in plant tissue cultures while repressing a cab gene encoding the chlorophyll a/b-binding protein of the light-harvesting antenna complex (Ohlsson et al. 1995; Henkow et al. 1996). 
Based on the above considerations, we aimed in this study to demonstrate the uncoupling effect of lipid peroxidation in spinach thylakoids exposed to peroxyl radicals generated by different concentrations of AAPH, by comparing 1) the relative susceptibilities of photosynthetic electron transport and $\Delta \mathrm{pH}$ to lipid peroxidation, and 2) the effects of $\mathrm{AAPH}$ on $\mathrm{O}_{2}$ uptake measured in presence and in absence of the artificial uncoupler $\mathrm{NH}_{4} \mathrm{Cl}$. We observed that the extent of lipid peroxidation was closely related to the inhibition of the light-induced $\Delta \mathrm{pH}$, which occurred at much lower concentrations than those required to inhibit significantly the photosynthetic electron transport. The uncoupling effect of AAPH, indicated by the presence of significant electron transport in absence of $\Delta \mathrm{pH}$, was confirmed by the stimulation at moderate AAPH concentrations of the $\mathrm{O}_{2}$ uptake measured in thylakoids resuspended in absence, but not in presence, of the artificial uncoupler $\mathrm{NH}_{4} \mathrm{Cl}$.

\section{Materials and Methods}

\section{Thylakoid isolation and treatments}

Thylakoids were isolated from fresh market spinach as in Whitmarsh and Ort (1984). Thylakoids were kept on ice in darkness and were used within 6-8 hours after their isolation. Chl $a+b$ concentration was estimated in $80 \%$ acetone according to Porra et al. (1989). For the treatments,

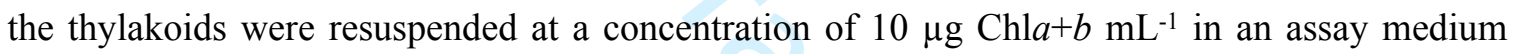
containing $200 \mathrm{mM}$ sorbitol, $25 \mathrm{mM}$ tricine- $\mathrm{NaOH}$ ( $\mathrm{pH} 8.0$ ), $5 \mathrm{mM} \mathrm{MgCl}_{2}$, and $0.5 \mathrm{mg} \mathrm{mL}^{-1} \mathrm{BSA}$ (fatty acid free). Thylakoids were incubated at $33^{\circ} \mathrm{C}$ for $20 \mathrm{~min}$ in presence of different AAPH concentrations ranging from 0 to $200 \mathrm{mM}$.

\section{Quantum yields of photosystem II photochemistry}

The chlorophyll- $a$ fluorescence (ChlF) was measured with a XE-PAM fluorimeter (Walz, Germany) to estimate the maximum $(\mathrm{Fv} / \mathrm{Fm})$ and effective $(\Delta \mathrm{F} / \mathrm{Fm}$ ') quantum yields of photosystem II photochemistry according to Klughammer and Schreiber (2008). Two mL of AAPH-treated thylakoids were placed in a quartz cuvette, and methyl viologen (MV) (0.3 mM) was added as an electron acceptor. Blue modulated $(2 \mathrm{~Hz})$ and non-actinic excitation was obtained by placing BG18, KV418, and neutral density filters in front of the Xe-flash lamp connected to the cuvette via a quartz rod. ChlF was collected via a plastic rod by a photodetector positioned at $90^{\circ}$ from the Xe-flash lamp, and protected with a RG715 Schott filter. The saturating light pulse and the actinic light $\left(90 \mu\right.$ moles photons $\left.\mathrm{m}^{-2} \mathrm{~s}^{-1}\right)$ were directed by an optic fiber placed just below the cuvette.

\section{Estimation of light-induced $\mathrm{pH}$ gradient}

Light-induced $\mathrm{pH}$ gradient $(\Delta \mathrm{pH})$ in spinach thylakoids was estimated by the quenching of the 9aminoacridine fluorescence (Q9-AA) (Schuldiner et al. 1972). This fluorescence was measured 
with the Xe-PAM fluorometer in the same configuration as for the ChlF measurements, except the presence of DUG11 + UG11 UV filters in front of the Xe-flash lamp, and the blue-green KV418 and BG18 filters in front of the photodetector. Two $\mathrm{mL}$ of treated thylakoids were placed in a quartz cuvette in presence of MV $(0.3 \mathrm{mM})$. After the recording of a baseline (F0), $1 \mu \mathrm{M}$ 9-aminoacrine was added to the cuvette and the unquenched signal of 9-aminoacrine fluorescence (F1) was measured in darkness. Then, the actinic light $\left(90 \mu\right.$ mole photons $\left.\mathrm{m}^{-2} \mathrm{~s}^{-1}\right)$ was turned on for $30 \mathrm{sec}$, sufficient to induce a quenched fluorescence level (F2). The Q9-AA related to $\Delta \mathrm{pH}$ was calculated as Q9-AA = $100 \times(\mathrm{F} 1-\mathrm{F} 2) /(\mathrm{F} 1-\mathrm{F} 0)$.

\section{Estimation of lipid peroxidation with the TBARS assay}

The thiobarbituric acid reactive substances (TBARS) assay is the most common estimation of lipid peroxidation in simple biological systems (Hodges et al. 1999). It is based on the absorbance at 532 $\mathrm{nm}$ of the complex formed between thiobarbituric acid and mainly malondialdehyde, one of the secondary products of lipid peroxidation.

At the end of the 20-min light treament, $0.1 \mathrm{~mL}$ of trichloroacetic acid (TCA) was added to $5.0 \mathrm{~mL}$ of a suspension of AAPH-treated thylakoids to stop the peroxidation reaction. Then, $2 \mathrm{~mL}$ of the thylakoid suspension were transferred to a test tube containing $2 \mathrm{~mL}$ TCA $30 \%, 0.2 \mathrm{~mL} \mathrm{HCl}$ $5 \mathrm{M}$, and $2 \mathrm{~mL}$ of thiobarbituric acid (TBA) $0.75 \%$. For each sample, the mixture was heated in a dry bath at $90^{\circ} \mathrm{C}$ for $45 \mathrm{~min}$, and then the samples were centrifuged for $10 \mathrm{~min}$ at $10000 \mathrm{~g}$ and $4^{\circ}$ C. The absorbance at $532 \mathrm{~nm}$ of the supernatant was measured, from which the non-specific absorbance at $600 \mathrm{~nm}$ was subtracted. The concentrations of MDA equivalents were calculated using an extinction coefficient of $155 \mathrm{mM}^{-1}$ (Hodges et al. 1999).

\section{Rates of photosynthetic electron transport measured by $\mathrm{O}_{2}$ uptake}

To complement the estimations of photochemical efficiency of photosystem II by ChlF, we also determined the rates of photosynthetic electron transport by $\mathrm{O}_{2}$ uptake measured with a Clark electrode connected to an Oxylab system (Hansatech, England). Immediately after the AAPH treatment, thylakoids were placed in the reaction vessel of a DW2/2 electrode chamber connected to a thermoregulated circulating water bath adjusted at $25^{\circ} \mathrm{C}$. MV $(0.3 \mathrm{mM})$ was added to the thylakoids maintained in darkness to record a drifting signal when present. Then, the thylakoids were illuminated with a saturating white light and the rate of $\mathrm{O}_{2}$ uptake was measured. After about 30 seconds, $1 \mathrm{mM} \mathrm{NH}_{4} \mathrm{Cl}$ was added to the thylakoids and the rate of $\mathrm{O}_{2}$ uptake by uncoupled thylakoids was measured.

\section{Statistical Analysis}

Data are the means $\pm \mathrm{SEM}$ calculated from five measurements made from five different thylakoid preparations, except for $\mathrm{O}_{2}$ evolution where $\mathrm{n}=3$. 


\section{Results}

In most experiments with AAPH such as ORAC assays, peroxyl radicals are generated at $37^{\circ} \mathrm{C}$, a temperature too high to ensure the stability of the thylakoids. Preliminary experiments were needed to determine the temperature and the duration of the treatments that optimize the production of peroxyl radicals by AAPH while maintaining the integrity of control thylakoids (without AAPH). To this end, we monitored the time-dependent bleaching of pyrogallol red (López-Alarcón and Lissi 2005) induced by the peroxyl radicals generated by AAPH at different temperatures. The absorbance of pyrogallol red linearly decreased at a rate that was directly temperature-dependent between $29^{\circ}$ and $37^{\circ} \mathrm{C}$ (Fig. S1). On the other hand, we observed that the quenching of the 9aminoacridine fluorescence (Q9-AA) in thylakoids without AAPH was stable over 30 min at temperatures from $29^{\circ}$ and $33^{\circ} \mathrm{C}$, but markedly decreased after $10 \mathrm{~min}$ at $35^{\circ} \mathrm{C}$ (Fig. S2). Therefore, a temperature of $33^{\circ} \mathrm{C}$ and a duration of 20 min were used for the AAPH treatments. The production rate of peroxyl radicals at $33^{\circ} \mathrm{C}$ was $66 \%$ relative to the rate at $37^{\circ} \mathrm{C}$ (Fig. S1B).

We then verified the effectiveness of the peroxyl radicals generated by AAPH to induce lipid peroxidation in spinach thylakoids under the selected experimental conditions ( $33^{\circ} \mathrm{C}$ x $\left.20 \mathrm{~min}\right)$. We detected the presence of TBA-MDA complexes (TBARS) at sub-millimolar AAPH concentrations, and their values increased exponentially with higher concentrations to reach a maximum near $100 \mathrm{mM}$ AAPH (Fig. 1).

The consequences of lipid peroxidation on the main functions of spinach thylakoids were assessed first by measuring the effects of different AAPH concentrations on the $\Delta \mathrm{pH}$ estimated by the Q9-AA (Fig.2). Inhibition of Q9-AA was already apparent at $0.1 \mathrm{mM} \mathrm{AAPH.} \mathrm{Q9-AA} \mathrm{values}$ decreased exponentially with increasing AAPH concentrations, and it was abolished between 10 and $20 \mathrm{mM}$ AAPH. The AAPH concentration required to inhibit by $50 \%$ the initial values $\left(\mathrm{IC}_{50}\right)$ of Q9-AA was estimated at $1.5 \mathrm{mM}$. Interestingly, the AAPH-induced inhibition of Q9-AA is closely correlated $\left(\mathrm{R}^{2}=0.981\right)$ to the presence of TBARS in spinach thylakoids treated with different AAPH concentrations (from 0 to $10 \mathrm{mM}$ ) (Fig.3).

Lipid peroxidation could inhibit the formation of light-induced $\Delta \mathrm{pH}$ either as a consequence of an increase in membrane leakiness to $\mathrm{H}^{+}$, or because of an inhibition of the photosynthetic electron transport. The most likely of these two possibilities was determined by measuring the maximum $(\mathrm{Fv} / \mathrm{Fm})$ and effective $(\Delta \mathrm{F} / \mathrm{Fm}$ ') quantum yields of PSII photochemistry (Fig. 4). Both quantum yields remained unaffected up to $2 \mathrm{mM}$ AAPH, but their values decreased exponentially at higher concentrations. The $\mathrm{IC}_{50}$ values were estimated at $120 \mathrm{mM}$ for $\mathrm{Fv} / \mathrm{Fm}$, and $40 \mathrm{mM}$ for $\Delta \mathrm{F} / \mathrm{Fm}$.

The much lower $\mathrm{IC}_{50}$ found for light-induced $\Delta \mathrm{pH}$ than for photosynthetic electron transport (1.5 vs $40 \mathrm{mM})$ indicates an uncoupling effect of AAPH in spinach thylakoids. This possibility was supported by measuring the rates of MV-supported $\mathrm{O}_{2}$ uptake in presence and in absence of the artificial uncoupler $\mathrm{NH}_{4} \mathrm{Cl}$. At $0 \mathrm{mM} \mathrm{AAPH}$, the uncoupling effect of $\mathrm{NH}_{4} \mathrm{Cl}$ can be seen by its large stimulation $(130 \%)$ of the rate of $\mathrm{O}_{2}$ uptake compared to the rate measured without $\mathrm{NH}_{4} \mathrm{Cl}$ (Fig. 5). As the concentration of AAPH increased, the rates of $\mathrm{O}_{2}$ uptake decreased in presence of $\mathrm{NH}_{4} \mathrm{Cl}$, similarly to the decline of $\Delta \mathrm{F} / \mathrm{Fm}$ '. In fact, the declines of the $\mathrm{O}_{2}$ uptake rates measured with $\mathrm{NH}_{4} \mathrm{Cl}$ and of $\Delta \mathrm{F} / \mathrm{Fm}$ ' are highly correlated $\left(\mathrm{R}^{2}=0.976\right)$ in thylakoids treated with different 
AAPH concentrations, (Fig. 6). A different response to AAPH was observed when $\mathrm{O}_{2}$ uptake rates were measured without $\mathrm{NH}_{4} \mathrm{Cl}$. The rates of $\mathrm{O}_{2}$ uptake increased at low AAPH concentrations, to reach a maximum at $10-20 \mathrm{mM}$, to a value $62 \%$ higher than the control value (no AAPH and no $\mathrm{NH}_{4} \mathrm{Cl}$ ). At 10-20 mM AAPH concentrations, the rates of $\mathrm{O}_{2}$ uptake in presence and in absence of $\mathrm{NH}_{4} \mathrm{Cl}$ became similar. Interestingly, $10-20 \mathrm{mM}$ correspond to the concentrations where AAPH completely inhibited Q9-AA. At higher AAPH concentrations, the rates of $\mathrm{O}_{2}$ uptake measured in presence and in absence of $\mathrm{NH}_{4} \mathrm{Cl}$ declined similarly.

\section{Discussion}

The production of NADPH and ATP by the light reactions in the thylakoid membranes requires the efficient coupling between the electron transport chain and the transfer of protons into the luminal spaces $(\Delta \mathrm{pH})$. Our results indicate that a slight lipid peroxidation in thylakoids induced by AAPHgenerated peroxyl radicals can alter membrane integrity that ensures this coupling. Indeed, we observed a close relation between the extent of lipid peroxidation and the inhibition of $\Delta \mathrm{pH}$ at low to moderate AAPH concentrations which still allowed substantial electron transport. This uncoupling effect of lipid peroxidation is supported by the $62 \%$ stimulation of $\mathrm{MV}$-mediated $\mathrm{O}_{2}$ uptake by thylakoids treated with moderate AAPH concentration $(10-20 \mathrm{mM})$.

An uncoupling effect of lipid peroxidation in spinach thylakoids is consistent with the reversible uncoupling of oxidative phosphorylation concomitant with the variations of TBARS concentrations observed in vivo in mitochondria isolated from rats after they received intraperitoneal injection of AAPH (Kanno et al. 1994). These authors observed that the extents of lipid peroxidation and uncoupling were maximum one hour after the injection and that the in vivo mitochondria gradually recovered to normal levels 14 hours later. This recovery is coherent with the transient photo-oxidative responses frequently occurring during plant acclimation to stresses (Muñoz et al. 2021).

It could be argued that the observed inhibitions of $\Delta \mathrm{pH}$ and electron transport could be the results of a direct effect of the AAPH compound altering the thylakoid structure instead of the consequence of lipid peroxidation initiated by the peroxyl radicals. Indeed, Isaakidou and Forti (1977) reported an uncoupling of electron transport from photophosphorylation in spinach thylakoids incubated in the dark with xanthine oxidase, a superoxide-producing enzyme. In that case, the uncoupling was observed in absence of xanthine, the enzyme substrate, and thus without the generation of $\mathrm{O}_{2}^{-}$. In our study, a direct effect of AAPH on membrane permeability to protons is unlikely considering 1) the hydrophilic nature of AAPH and 2) the strong correlation observed between the extents of lipid peroxidation (TBARS) and the inhibition of $\Delta \mathrm{pH}$ with increasing AAPH concentrations. However, we cannot rule out that the inhibitions of electron transport observed at the highest concentration used in our study was the result of both membrane peroxidation and due to a direct effect of AAPH on the components of the electron transport chain.

Numerous studies have used AAPH as a model reagent to study the consequences of oxidative damages on whole organisms, cell cultures, erythrocytes or artificial membranes. The AAPH effects on biomembranes have been more extensively studied in erythrocytes, where radical chain oxidation of membrane components eventually causes hemolysis (Takahashi and Niki 1998). 
At an early stage of the peroxidation process in erythrocytes, there is a leakage of $\mathrm{K}^{+}$, then $\mathrm{Ca}^{2+}$. Further peroxidation causes the accumulation of secondary peroxidation products, concurrently with the oxidation and redistribution of the band 3 protein. These reactions result in the formation of hemolytic holes responsible for the leakage of hemoglobin and other proteins (Sato et al. 1992; Sato et al. 1995). Interestingly, the $\mathrm{IC}_{50}$ for the AAPH-induced hemolysis of erythrocytes after 1 hour at $37^{\circ} \mathrm{C}$ (about $75 \mathrm{mM}$ ) is much higher than the $\mathrm{IC}_{50}$ of Q9-AA inhibition $(1.5 \mathrm{mM}$ ) that we observed after a milder incubation of 20 minutes at $33^{\circ} \mathrm{C}$. A lower $\mathrm{IC}_{50}$ and then a larger difference between thylakoids and mitochondria may have been observed since the incubation at $33^{\circ} \mathrm{C}$ for 20 min, even if thylakoid integrity was ensured during this period (Fig. 2), may have increased the thylakoid fluidity, consequently increasing their susceptibility to peroxyl radicals. Still, this large difference of $\mathrm{EC}_{50}$ indicates that minor alteration of the thylakoid membranes is sufficient to increase its permeability to protons, whereas more extensive oxidation of membrane components (both lipids and proteins) is necessary to form hemolytic holes in erythrocyte membranes. The large difference of $\mathrm{IC}_{50}$ between thylakoids and erythrocytes exposed to AAPH might also originate from their different lipid composition: thylakoids possess distinctive polar head groups, notably the dominant di- and monogalactosyldiacylglycerol (DGDG,and MGDG) associated with a large proportion of polyunsaturated fatty acids (Sakurai et al. 2006; Van Eerden et al. 2015) compared to the typical phosphoglycerides (ethanolamine, serine and choline) with less unsaturated fatty acids present in the erythrocyte membrane (Krachler et al. 2008). Besides the main lipid composition, the presence of $\alpha$-tocopherol (Vit E), an efficient quencher of peroxidation, was shown to significantly delay the AAPH-induced hemolysis of erythrocytes (Mino et al. 1988). Interestingly, $\alpha$-tocopherol contributes to plant stress tolerance since its levels in thylakoids can change significantly during plant development and in response to environmental stress (MunnéBosch 2005).

Besides the effects of AAPH on rat mitochondria, other observations from the literature indirectly support an uncoupling effect of lipid peroxidation in chloroplasts. Indeed, there are several examples of inhibition of ATP synthesis in plants exposed to various environmental stresses (Ortiz-Lopez et al. 1991; Tezara et al. 1999; Lawlor and Cornic 2002; Allakhverdiev et al. 2008). Although inhibition of ATP synthesis can also result from the inactivation of the F-ATPase and from the inhibition of the photosynthetic electron transport, only the uncoupling of thylakoids can cause an inhibition of non-photochemical quenching (qN) accompanied by an overreduction of the photosynthetic electron transport chain (i.e., a decrease of photochemical quenching qP). Such simultaneous decreases of both $\mathrm{qN}$ and $\mathrm{qP}$ have been reported in a variety of environmental stresses: low temperatures (Strand and Öquist 1988), ozone (Calatayud et al. 2002), copper (Pádua et al. 2010), acid rain (Qiu and Liu 2002), and methyl viologen (Samson et al. 2020). To further support our conclusions, it would have been interesting to directly measure the inhibition of qN formation in thylakoids treated with low to moderate AAPH concentrations. However, activation of $\mathrm{qN}$ requires prolonged (10-20 $\mathrm{min}$ ) of illumination not feasible in our conditions, or the accumulation of zeaxanthin in thylakoids just before their isolation by the pre-illumination of the leaves, ideally in $\mathrm{CO}_{2}$-free atmosphere for $50 \mathrm{~min}$ in the presence of $200 \mu \mathrm{mol} \mathrm{m} \mathrm{m}^{-2} \mathrm{~s}^{-1}$ (Noctor et al. 1991).

Loss of $\mathrm{qN}$ and overreduction of the plastoquinone (PQ) pool caused by increased $\mathrm{H}^{+}$leakiness of thylakoid membranes promote photoinhibition and ROS production. Fortunately, 
reduction of the photosynthetic electron chain, mainly the PQ pool and the ferredoxin/thioredoxin system, can activate signaling pathways that lead to appropriate acclimation in response to photooxidative stress (Yang et al. 2001; Havaux 2020). For instance, it was shown in Lemna minor that a more reduced PQ pool caused by inhibitors of $\mathrm{PQH}_{2}$ oxidation by the cytochrome $\mathrm{b}_{6} \mathrm{f}$ complex stimulate the synthesis of polyphenols, more specifically flavonoids (Akhtar et al. 2010). These secondary metabolites accumulate in plants exposed to diverse environmental stresses such as heavy metals, ozone, herbivory, drought, nutrient limitations, etc. (Dixon and Paiva 1995). Also, exogenous salicylic acid increases polyphenol contents in plants (Chitra et al. 2008), and improves plant resistance against biotic (Chitra et al. 2008) and abiotic (Hayat et al. 2010) stresses. Interestingly, salicylic acid was shown to act as an uncoupler in mitochondria (Norman et al. 2004). Like the dual role of ROS as both damaging and signaling molecules (Noctor et al. 2018), the uncoupling effect of lipid peroxidation could inhibit ATP synthesis but on the other hand, it could activate via a more reduced PQ pool a complex network of pathways, leading to the acclimation of the photosynthetic system to the stress conditions.

In short, our results demonstrate that moderate lipid peroxidation induced by peroxyl radicals caused the uncoupling of spinach thylakoids. We suggest that the increased $\mathrm{H}^{+}$-leakiness of thylakoid membranes could be one of the primary effects of mild oxidative stress in chloroplasts.

\section{Credit authorship contribution statement}

O La Haye Yergeau: Realization of most of the experiments, data analysis, reading and approval the manuscript.

G Samson: Conception of the experiments, realization of some experiments (TBARS and $\mathrm{O}_{2}$ uptake), supervision, data analysis, writing the manuscript.

\section{Declaration of Competing Interest}

The authors report no declarations of interest.

\section{Acknowledgments}

OLY was supported by a Student Research Awards from the Natural Sciences and Engineering Research Council of Canada.

\section{References}

Akhtar, T., H. Lees, M. Lampi, D. Enstone, R. Brain, and B.M. Greenberg, 2010. Photosynthetic redox imbalance influences flavonoid biosynthesis in Lemna gibba. Plant Cell Environ. 33(7): 1205-1219. doi 10.1111/j.1365-3040.2010.02140.x. 
Allakhverdiev, S.I., V.D. Kreslavski, V.V. Klimov, D.A. Los, R. Carpentier, and P. Mohanty, 2008. Heat stress: An overview of molecular responses in photosynthesis. Photosynth. Res. 98(13): 541-550. doi 10.1007/s11120-008-9331-0.

Apel, K., and H. Hirt, 2004. Reactive oxygen species: Metabolism, oxidative stress, and signal transduction. In Annual Review of Plant Biology. Vol. 55. 373-399 10.1146/annurev.arplant.55.031903.141701.

Asada, K., 2006. Production and scavenging of reactive oxygen species in chloroplasts and their functions. Plant Physiol. 141(2): 391-396. doi 10.1104/pp.106.082040.

Calatayud, A., J.W. Alvarado, and E. Barreno, 2002. Differences in ozone sensitivity in three varieties of cabbage (Brassica oleracea L.) in the rural Mediterranean area. J. Plant Physiol. 159(8): 863-868. doi 10.1078/0176-1617-00586.

Chitra, K., N. Ragupathi, K. Dhanalakshmi, P. Mareeshwari, N. Indra, A. Kamalakannan, A. Sankaralingam, and R. Rabindran, 2008. Salicylic acid induced systemic resistant on peanut against Alternaria alternata. Arch. Phytopathol. Plant Prot. 41(1): 50-56. doi. $10.1080 / 03235400600655263$

Dean, R. L. and E. Miskiewicz (2003) Rates of electron transport in the thylakoid membranes of isolated, illuminated chloroplasts are enhanced in the presence of ammonium chloride. Biochem. Mol. Biol. Edu. 31 (6): 410-417. doi. 10.1002/bmb.2003.494031060265

Dietz, K.J., I. Turkan, and A. Krieger-Liszkay, 2016. Redox- and reactive oxygen speciesdependent signaling into and out of the photosynthesizing chloroplast. Plant Physiol. 171(3): 1541-1550. doi 10.1104/pp.16.00375.

Dixon, R.A., and N.L. Paiva, 1995. Stress-induced phenylpropanoid metabolism. Plant Cell. 7(7): 1085-1097. doi 10.1105/tpc.7.7.1085.

Dubovskaya, L.V., E.V. Kolesneva, D.M. Knyazev, and I.D. Volotovskii, 2007. Protective role of nitric oxide during hydrogen peroxide-induced oxidative stress in tobacco plants. Russ. J. Plant Physiol. 54(6): 755-762. doi 10.1134/S1021443707060064.

Farhat, N., A.G. Ivanov, M. Krol, M. Rabhi, A. Smaoui, C. Abdelly, and N.P.A. Hüner, 2015. Preferential damaging effects of limited magnesium bioavailability on photosystem I in Sulla carnosa plants. Planta. 241(5): 1189-1206. doi 10.1007/s00425-015-2248-x.

Foyer, C.H., A.V. Ruban, and G. Noctor, 2017. Viewing oxidative stress through the lens of oxidative signalling rather than damage. Biochem. J. 474(6): 877-883. doi 10.1042/BCJ20160814.

Gomes, M.D.M., G.M.C. Carvalho, N.V. Casquilho, A.C.P. Araújo, S.S. Valença, J.H. LealCardoso, and W.A. Zin, 2016. 2,2'-azobis (2-amidinopropane) dihydrochloride is a useful tool to impair lung function in rats. Front. Physiol. 7(OCT): doi 10.3389/fphys.2016.00475.

Gupta, A.S., R.G. Alscher, and D. McCune, 1991. Response of photosynthesis and cellular antioxidants to ozone in Populus leaves. Plant Physiol. 96(2): 650-655. doi 10.1104/pp.96.2.650.

Halliwell, B., 1987. Oxidative damage, lipid peroxidation and antioxidant protection in chloroplasts. Chem. Phys. Lipids. 44(2-4): 327-340. doi 10.1016/0009-3084(87)90056-9.

Havaux, M., 2020. Plastoquinone in and beyond photosynthesis. Trends Plant Sci. 25 (12): 12521265. doi 10.1016/j.tplants.2020.06.011.

Hayat, Q., S. Hayat, M. Irfan, and A. Ahmad, 2010. Effect of exogenous salicylic acid under changing environment: A review. Environ. Exp. Bot. 68(1): 14-25. doi. 10.1016/j.envexpbot.2009.08.005

He, R.R., Y. Li, X.D. Li, R.N. Yi, X.Y. Wang, B. Tsoi, K.K.H. Lee, K. Abe, X. Yang, and H. Kurihara, 2013. A New Oxidative Stress Model, 2,2-Azobis(2-Amidinopropane) Dihydrochloride Induces Cardiovascular Damages in Chicken Embryo. PLoS ONE. 8(3): doi 10.1371/journal.pone.0057732. 
Henkow, L., Å. Strid, T. Berglund, J. Rydström, and A.B. Ohlsson, 1996. Alteration of gene expression in Pisum sativum tissue cultures caused by the free radical-generating agent 2,2'-azobis (2-amidinopropane) dihydrochloride. Physiol. Plant. 96(1): 6-12. doi 10.1111/j.1399-3054.1996.tb00176.x.

Hideg, É., and I. Vass, 1996. UV-B induced free radical production in plant leaves and isolated thylakoid membranes. Plant Sci. 115(2): 251-260. doi 10.1016/0168-9452(96)04364-6.

Hodges, D.M., J.M. DeLong, C.F. Forney, and R.K. Prange, 1999. Improving the thiobarbituric acid-reactive-substances assay for estimating lipid peroxidation in plant tissues containing anthocyanin and other interfering compounds. Planta. 207(4): 604-611. doi $10.1007 / \mathrm{s} 004250050524$.

Isaakidou, J., and G. Forti, 1977. Uncoupling of chloroplast electron transport by xanthine oxidase. Plant Sci. Lett. 9(1): 65-69. doi 10.1016/0304-4211(77)90012-8.

Kanno, T., T. Utsumi, A. Ide, Y. Takehara, T. Saibara, J. Akiyama, T. Yoshioka, and K. Utsumi, 1994. Dysfunction of mouse liver mitochondria induced by 2,2'azobis-(2-amidinopropane) dihydrochloride, a radical initiator, in vitro and in vivo. Free Radic. Res. 21(4): 223-234. doi 10.3109/10715769409056574.

Klughammer, C., and U. Schreiber, 2008. Complementary PS II quantum yields calculated from simple fluorescence parameters measured by PAM fluorometry and the Saturation Pulse method. PAM Appl Notes 1: 27-35.

Krachler, B., M. Norberg, J.W. Eriksson, G. Hallmans, I. Johansson, B. Vessby, L. Weinehall, and B. Lindahl, 2008. Fatty acid profile of the erythrocyte membrane preceding development of Type 2 diabetes mellitus. Nutr. Metab. Cardiovasc. Dis. 18(7): 503-510. doi 10.1016/j.numecd.2007.04.005.

Lawlor, D.W., and G. Cornic, 2002. Photosynthetic carbon assimilation and associated metabolism in relation to water deficits in higher plants. Plant Cell Environ. 25(2): 275-294. doi 10.1046/j.0016-8025.2001.00814.x.

López-Alarcón, C., and E. Lissi, 2005. Interaction of pyrogallol red with peroxyl radicals. A basis for a simple methodology for the evaluation of antioxidant capabilities. Free Radic. Res. 39(7): 729-736. doi 10.1080/10715760500143452.

Ma, J., C. Lv, M. Xu, G. Chen, C. Lv, and Z. Gao, 2016. Photosynthesis performance, antioxidant enzymes, and ultrastructural analyses of rice seedlings under chromium stress. Environ. Sci. Pollut. Res. 23(2): 1768-1778. doi 10.1007/s11356-015-5439-x.

Mendez-Sanchez, S.C., G.R. Martinez, S. Romão, A. Echevarria, E.F. Silva, M.E.M. Rocha, G.R. Noleto, E.G.S. Carnieri, S.M.S.C. Cadena, and M.B.M. de Oliveira, 2009. The inhibition of lipoperoxidation by mesoionic compound MI-D: A relationship with its uncoupling effect and scavenging activity. Chem.-Biol. Interact. 179(2-3): 125-130. doi 10.1016/j.cbi.2008.11.016.

Mino, M., M. Miki, H. Tamai, H. Yasuda, and H. Maeda, 1988. Membrane damage in erythrocytes induced by radical initiating reactions and the effect of tocopherol as a radical scavenger. In Lipid Peroxidation in Biological Systems. Vol. 4. A. Sevanian, editor. American Oil Chemists' Society, Champaign IL, USA. p. 51-70

Mittler, R., 2002. Oxidative stress, antioxidants and stress tolerance. Trends Plant Sci. 7(9): 405410. doi 10.1016/S1360-1385(02)02312-9.

Munné-Bosch, S., 2005. The role of $\alpha$-tocopherol in plant stress tolerance. J. Plant Physiol. 162(7): 743-748. doi 10.1016/j.jplph.2005.04.022.

Muñoz, P., A. Cotado, and S. Munné-Bosch, 2021. Transient photoinhibition and photo-oxidative stress as an integral part of stress acclimation and plant development in a dioecious tree adapted to Mediterranean ecosystems. Tree Physiol 41(7):1212-1229. doi 10.1093/treephys/tpaa177.

Niki, E., 1990. Free radical initiators as source of water- or lipid-soluble peroxyl radicals. In Methods in Enzymology. Vol. 186. 100-108 10.1016/0076-6879(90)86095-D. 
Noctor, G., Rees, D., Young, A., Horton, P. (1991) The relationship between zeaxanthin, energydependent quenching of chlorophyll fluorescence, and trans-thylakoid $\mathrm{pH}$ gradient in isolated chloroplasts. BBA - Bioenergetics 1057(3): 320-330. 10.1016/S00052728(05)80143-4

Noctor, G., and C.H. Foyer, 1998. Ascorbate and glutathione: keeping active oxygen under control. In Annual Review of Plant Biology. Vol. 49. Annual Reviews Inc. 249-279 10.1146/annurev.arplant.49.1.249.

Noctor, G., J.P. Reichheld, and C.H. Foyer, 2018. ROS-related redox regulation and signaling in plants. Semin. Cell. Dev. Biol. 80(3-12. doi 10.1016/j.semcdb.2017.07.013.

Norman, C., K.A. Howell, A.H. Millar, J.M. Whelan, and D.A. Day, 2004. Salicylic acid is an uncoupler and inhibitor of mitochondrial electron transport. Plant Physiol. 134(1): 492501. doi. 10.1104/pp.103.031039

Ohlsson, A.B., T. Berglund, P. Komlos, and J. Rydström, 1995. Plant defense metabolism is increased by the free radical-generating compound AAPH. Free Radic. Biol. Med. 19(3): 319-327. doi 10.1016/0891-5849(95)00022-P.

Ortiz-Lopez, A., D.R. Ort, and J.S. Boyer, 1991. Photophosphorylation in attached leaves of Helianthus annuus at low water potentials. Plant Physiol. 96(4): 1018-1025. doi 10.1104/pp.96.4.1018.

Pádua, M., A.M. Cavaco, S. Aubert, R. Bligny, and A. Casimiro, 2010. Effects of copper on the photosynthesis of intact chloroplasts: Interaction with manganese. Physiol. Plant. 138(3): 301-311. doi 10.1111/j.1399-3054.2009.01335.x.

Pathak, V., A. Prasad, and P. Pospíšil, 2017. Formation of singlet oxygen by decomposition of protein hydroperoxide in photosystem II. PLoS ONE. 12(7): doi 10.1371/journal.pone.0181732.

Porra, R.J., W.A. Thompson, and P.E. Kriedemann, 1989. Determination of accurate extinction coefficients and simultaneous equations for assaying chlorophylls a and $\mathrm{b}$ extracted with four different solvents: verification of the concentration of chlorophyll standards by atomic absorption spectroscopy. Biochim. Biophys. Acta Bioenerg. 975(3): 384-394. doi 10.1016/S0005-2728(89)80347-0.

Pospíśil, P., 2016. Production of reactive oxygen species by photosystem II as a response to light and temperature stress. Front. Plant Sci. 7(December2016): doi 10.3389/fpls.2016.01950.

Pospíšil, P., and Y. Yamamoto, 2017. Damage to photosystem II by lipid peroxidation products. Biochim. Biophys. Acta Gen. Subj. 1861(2): 457-466. doi 10.1016/j.bbagen.2016.10.005.

Prasad, S.M., and M. Zeeshan, 2005. UV-B radiation and cadmium induced changes in growth, photosynthesis, and antioxidant enzymes of cyanobacterium Plectonema boryanum. Biol. Plant. 49(2): 229-236. doi 10.1007/s10535-005-0236-x.

Prior, R.L., X. Wu, and K. Schaich, 2005. Standardized methods for the determination of antioxidant capacity and phenolics in foods and dietary supplements. J. Agric. Food Chem. 53(10): 4290-4302. doi 10.1021/jf0502698.

Qiu, D., and X. Liu, 2002. Effects of simulated acid rain on chloroplast activity in Dimorcarpus longana Lour. cv. wulongling leaves. Chin. J. Appl. Ecol. 13(12): 1559-1562. doi.

Rawyler, A., S. Arpagaus, and R. Braendle, 2002. Impact of oxygen stress and energy availability on membrane stability of plant cells. Ann. Bot. 90(4): 499-507. doi 10.1093/aob/mcf126.

Sakurai, I., J.R. Shen, J. Leng, S. Ohashi, M. Kobayashi, and H. Wada, 2006. Lipids in oxygenevolving photosystem II complexes of cyanobacteria and higher plants. J. Biochem. 140(2): 201-209. doi 10.1093/jb/mvj141.

Samson, G., Z.G. Cerovic, W.M.A. El Rouby, and P. Millet, 2020. Oxidation of polyphenols and inhibition of photosystem II under acute photooxidative stress. Planta. 251(1): doi 10.1007/s00425-019-03316-x. 
Sato, T., I. Kawaguchi, T. Fujii, and A. Tamura, 1992. Oxidative membrane damage and the resulting alteration in the membrane lipid bilayer structure of human erythrocytes caused by radical-forming oxidants. J. Clin. Biochem. Nutr. 12(3): 141-152. doi $10.3164 /$ jcbn.12.141.

Sato, Y., S. Kamo, T. Takahashi, and Y. Suzuki, 1995. Mechanism of free radical-induced hemolysis of human erythrocytes: hemolysis by water-soluble radical initiator. Biochemistry. 34(28): 8940-8949. doi 10.1021/bi00028a002.

Schuldiner, S., H. Rottenberg, and M. Avron, 1972. Determination of $\Delta \mathrm{pH}$ in chloroplasts: 2. fluorescent amines as a probe for the determination of $\delta \mathrm{ph}$ in chloroplasts. Eur. J. Biochem. 25(1): 64-70. doi 10.1111/j.1432-1033.1972.tb01667.x.

Schwertner, H.A., and J.B. Biale, 1973. Lipid composition of plant mitochondria and of chloroplasts. J. Lipid Res. 14(2): 235-242.

Strand, M., and G. Öquist, 1988. Effects of frost hardening, dehardening and freezing stress on in vivo chlorophyll fluorescence of seedlings of Scots pine (Pinus sylvestris L.). Plant Cell Environ. 11(4): 231-238. doi 10.1111/j.1365-3040.1988.tb01141.x.

Takahashi, M., and E. Niki, 1998. The effect of oxidative stress on cells by oxygen radicals and its inhibition by antioxidants. In Oxidative Stress in Cancer, AIDS and Neurodegenerative Diseases. L. Montagnier, R. Olivier and C. Pasquier, editors. Taylor \& Francis. 9-14

Tezara, W., V.J. Mitchell, S.D. Driscoll, and D.W. Lawlor, 1999. Water stress inhibits plant photosynthesis by decreasing coupling factor and ATP. Nature. 401(6756): 914-917. doi $10.1038 / 44842$.

Van Eerden, F.J., D.H. De Jong, A.H. De Vries, T.A. Wassenaar, and S.J. Marrink, 2015. Characterization of thylakoid lipid membranes from cyanobacteria and higher plants by molecular dynamics simulations. Biochim. Biophys. Acta Biomembr. 1848(6): 1319-1330. doi 10.1016/j.bbamem.2015.02.025.

Wang, L., W.W. Lee, H.W. Yang, B.M. Ryu, Y.R. Cui, S.C. Lee, T.G. Lee, and Y.J. Jeon, 2018. Protective effect of water extract of citrus pomace against AAPH-induced oxidative stress in vitro in Vero cells and in vivo in zebrafish. Prevent. Nutrition Food Sci. 23(4): 301-308. doi 10.3746/pnf.2018.23.4.301.

Whitmarsh, J., and D.R. Ort, 1984. Stoichiometries of electron transport complexes in spinach chloroplasts. Arch. Biochem. Biophys. 231(2): 378-389. doi 10.1016/00039861(84)90401-6.

Yalcinkaya, T., B. Uzilday, R. Ozgur, I. Turkan, and J. Mano, 2019. Lipid peroxidation-derived reactive carbonyl species (RCS): Their interaction with ROS and cellular redox during environmental stresses. Environ. Exp. Bot. 165:139-149. doi 10.1016/j.envexpbot.2019.06.004.

Yamauchi, Y., A. Furutera, K. Seki, Y. Toyoda, K. Tanaka, and Y. Sugimoto, 2008. Malondialdehyde generated from peroxidized linolenic acid causes protein modification in heat-stressed plants. Plant Physiol. Biochem. 46(8-9): 786-793. doi 10.1016/j.plaphy.2008.04.018.

Yan, K., S. Zhao, M. Cui, G. Han, and P. Wen, 2018. Vulnerability of photosynthesis and photosystem I in Jerusalem artichoke (Helianthus tuberosus L.) exposed to waterlogging. Plant Physiol. Biochem. 125:239-246. doi 10.1016/j.plaphy.2018.02.017.

Yang, D.H., B. Andersson, E.M. Aro, and I. Ohad, 2001. The redox state of the plastoquinone pool controls the level of the light-harvesting chlorophyll $\mathrm{a} / \mathrm{b}$ binding protein complex II (LHC II) during photoacclimation: Cytochrome b6f deficient Lemna perpusilla plants are locked in a state of high-light acclimation. Photosynth. Res. 68(2): 163-174. doi 10.1023/A:1011849919438.

Yoshida, Y., N. Itoh, Y. Saito, M. Hayakawa, and E. Niki, 2004. Application of water-soluble radical initiator, 2,2'-azobis-[2-(2-imidazolin-2-yl)propane] dihydrochloride, to a study of oxidative stress. Free Radic. Res. 38(4): 375-384. doi 10.1080/1071576042000191763. 
Yousuf, P.Y., A. Ahmad, A.H. Ganie, O. Sareer, V. Krishnapriya, I.M. Aref, and M. Iqbal, 2017. Antioxidant response and proteomic modulations in Indian mustard grown under salt stress. Plant Growth Regul. 81(1): 31-50. doi 10.1007/s10725-016-0182-y.

Zheng, C., D. Jiang, F. Liu, T. Dai, Q. Jing, and W. Cao, 2009. Effects of salt and waterlogging stresses and their combination on leaf photosynthesis, chloroplast ATP synthesis, and antioxidant capacity in wheat. Plant Sci. 176(4): 575-582. doi 10.1016/j.plantsci.2009.01.015.

Zlobin, I.E., A.V. Kartashov, P.P. Pashkovskiy, Y.V. Ivanov, V.D. Kreslavski, and V.V. Kuznetsov, 2019. Comparative photosynthetic responses of Norway spruce and Scots pine seedlings to prolonged water deficiency. J. Photochem. Photobiol. B Biol. 201(doi 10.1016/j.jphotobiol.2019.111659.

Zou, C.G., N.S. Agar, and G.L. Jones, 2001. Oxidative insult to human red blood cells induced by free radical initiator AAPH and its inhibition by a commercial antioxidant mixture. Life Sci. 69(1): 75-86. doi 10.1016/S0024-3205(01)01112-2. 


\section{Figure legends}

Figure 1 Concentrations of thiobarbituric acid reactive substances (TBARS) as markers of lipid peroxidation in spinach thylakoids exposed to peroxyl radicals generated by different concentrations of AAPH for $20 \mathrm{~min}$ at $33^{\circ} \mathrm{C}$. Symbols represent the means $(\mathrm{n}=5)$ and the error bars, the standard errors of the mean.

Figure 2 Decrease of the light-induced quenching of the 9-aminoacridine fluorescence Q9-AA in spinach thylakoids incubated in presence of different concentrations of AAPH. Symbols represent the means $(n=5)$ and the error bars, the standard errors of the mean.

Figure 3 Correlation between the values of the light-induced quenching of the 9-aminoacridine fluorescence Q9-AA and the TBARS concentrations in spinach thylakoids incubated in presence of different concentrations of AAPH.

Figure 4 Decreases of the maximum $(\mathrm{Fv} / \mathrm{Fm} \bullet)$ and effective $\left(\Delta \mathrm{F} / \mathrm{Fm}{ }^{\prime} \circ\right)$ quantum yields of Photosystem II photochemistry measured from spinach thylakoids exposed to peroxyl radicals generated by different concentrations of AAPH. Symbols represent the means $(n=5)$ and the error bars, the standard errors of the mean.

Figure 5 Rates of methyl viologen-supported $\mathrm{O}_{2}$ uptake by spinach thylakoids exposed to peroxyl radicals generated by different concentrations of $\mathrm{AAPH} . \mathrm{O}_{2}$ uptake was measured in absence $(\mathrm{O})$ and in presence $(\bullet)$ of the uncoupler $\mathrm{NH}_{4} \mathrm{Cl}(1 \mathrm{mM})$.

Figure 6 Correlation between the effective quantum yield of Photosystem II photochemistry $\Delta \mathrm{F} / \mathrm{Fm}$ ' and the rates of methyl viologen-supported $\mathrm{O}_{2}$ uptake measured in presence of $\mathrm{NH}_{4} \mathrm{Cl}$ from spinach thylakoids exposed to peroxyl radicals generated by different concentrations of AAPH. Symbols represent the means $(n=3)$ and the error bars, the standard errors of the mean. 


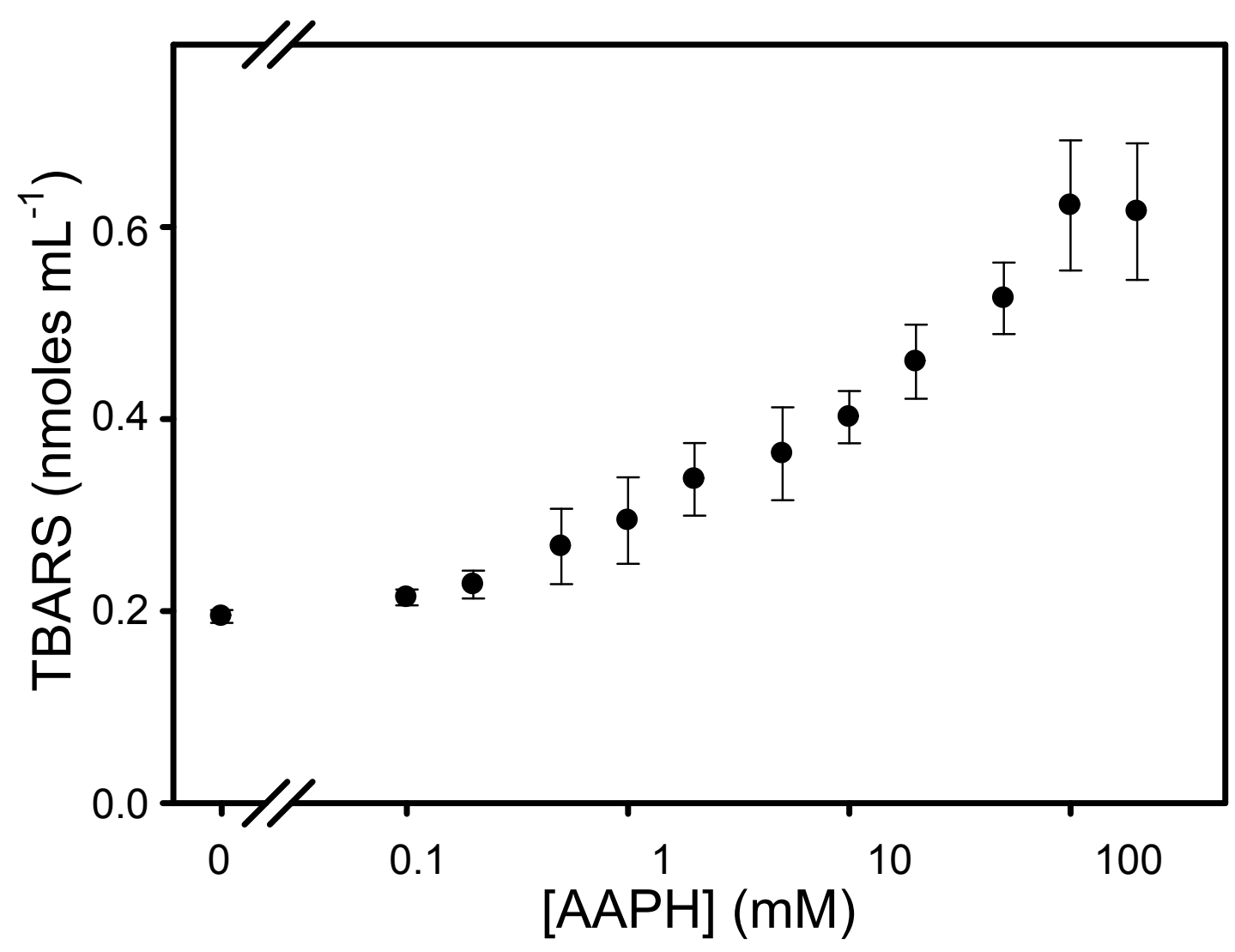

Figure 1 


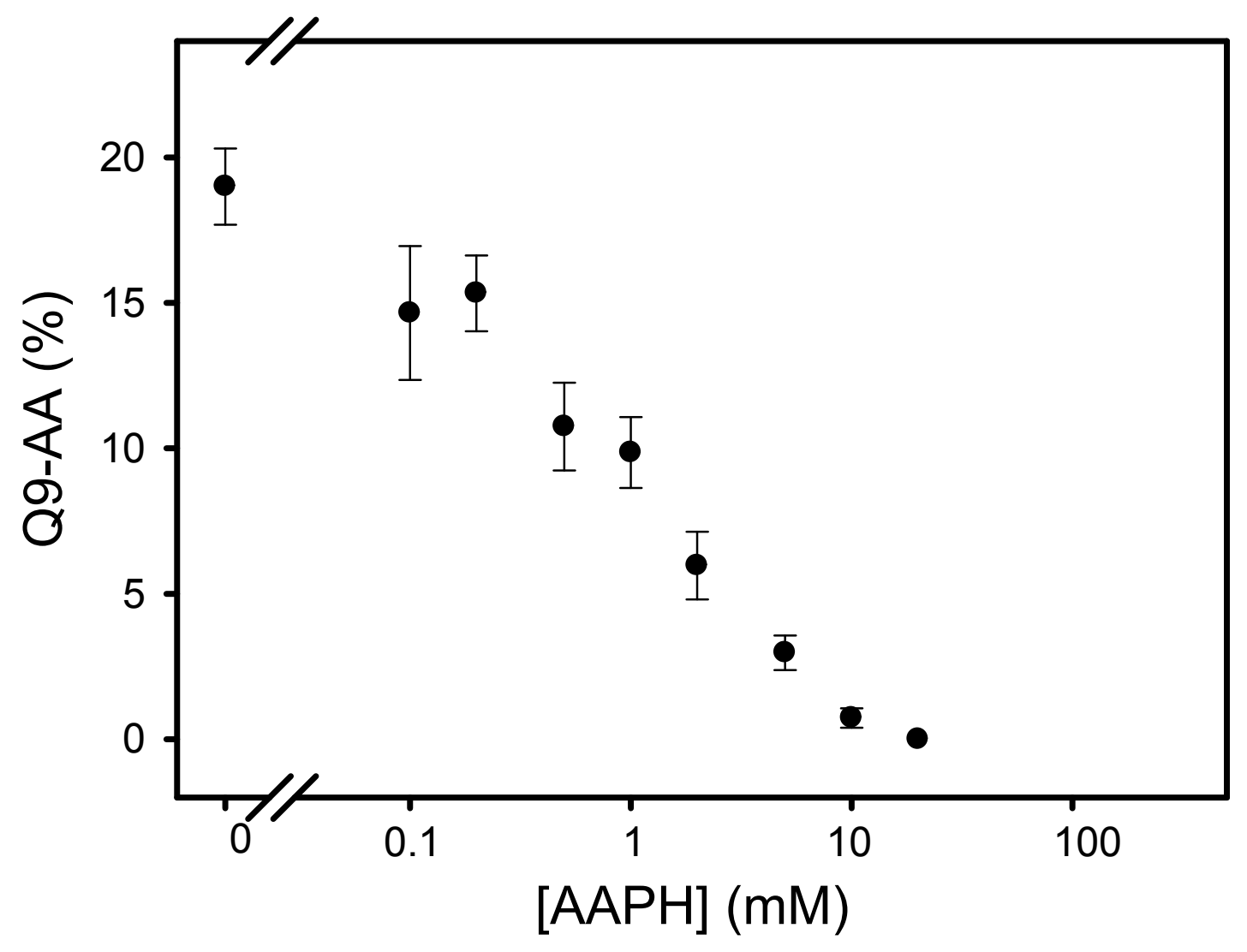

Figure 2 


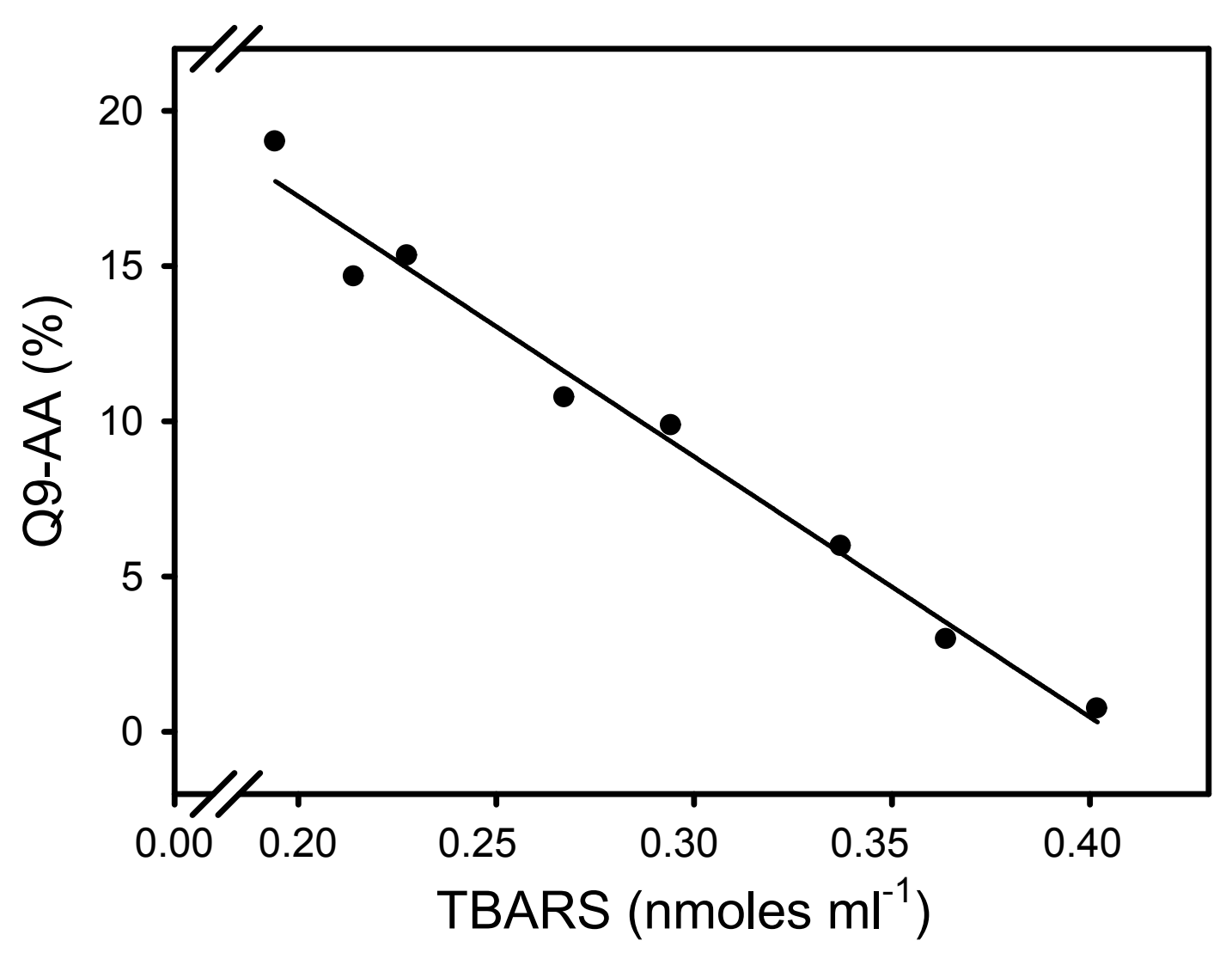

Figure 3 


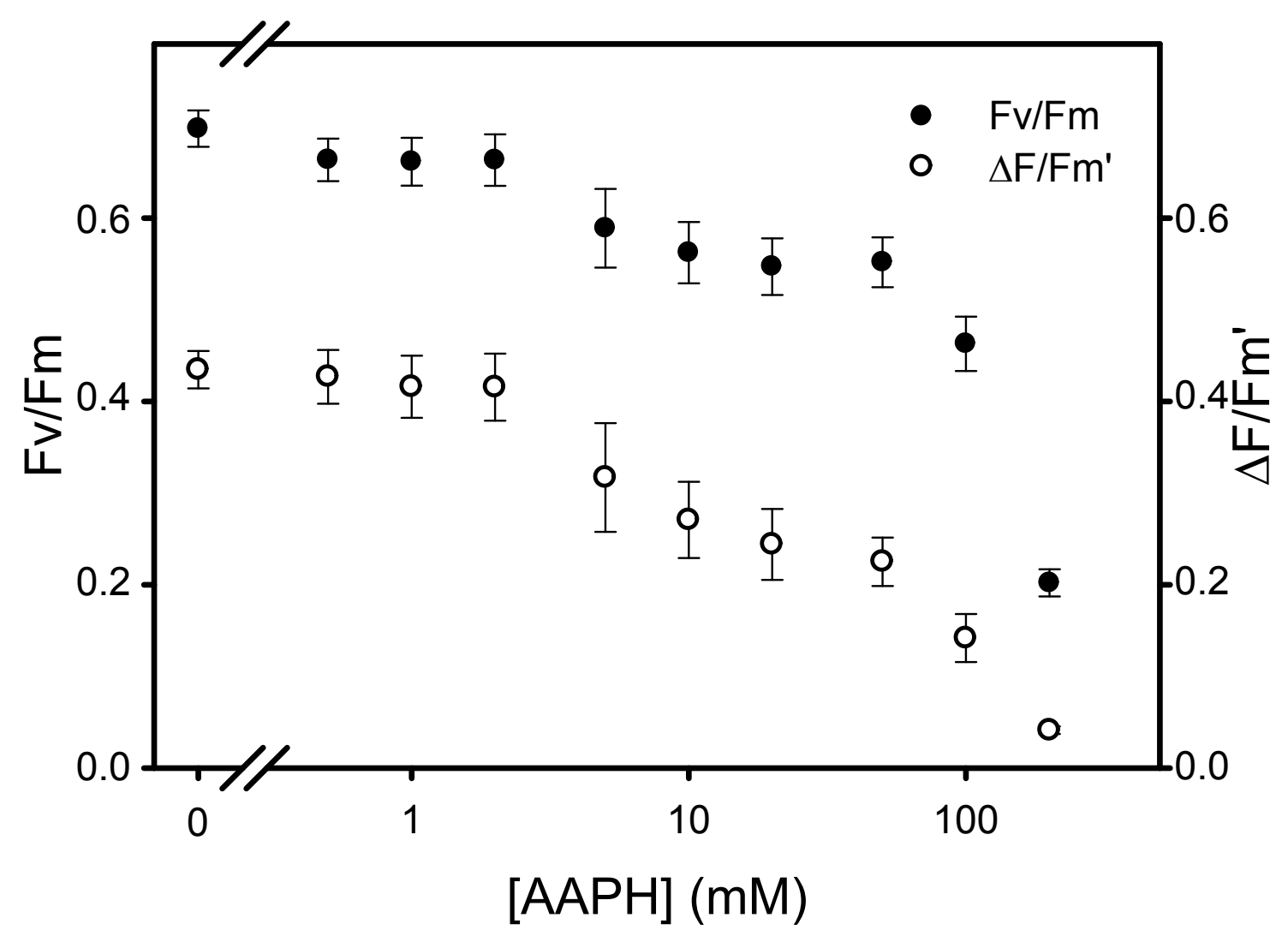

Figure 4 


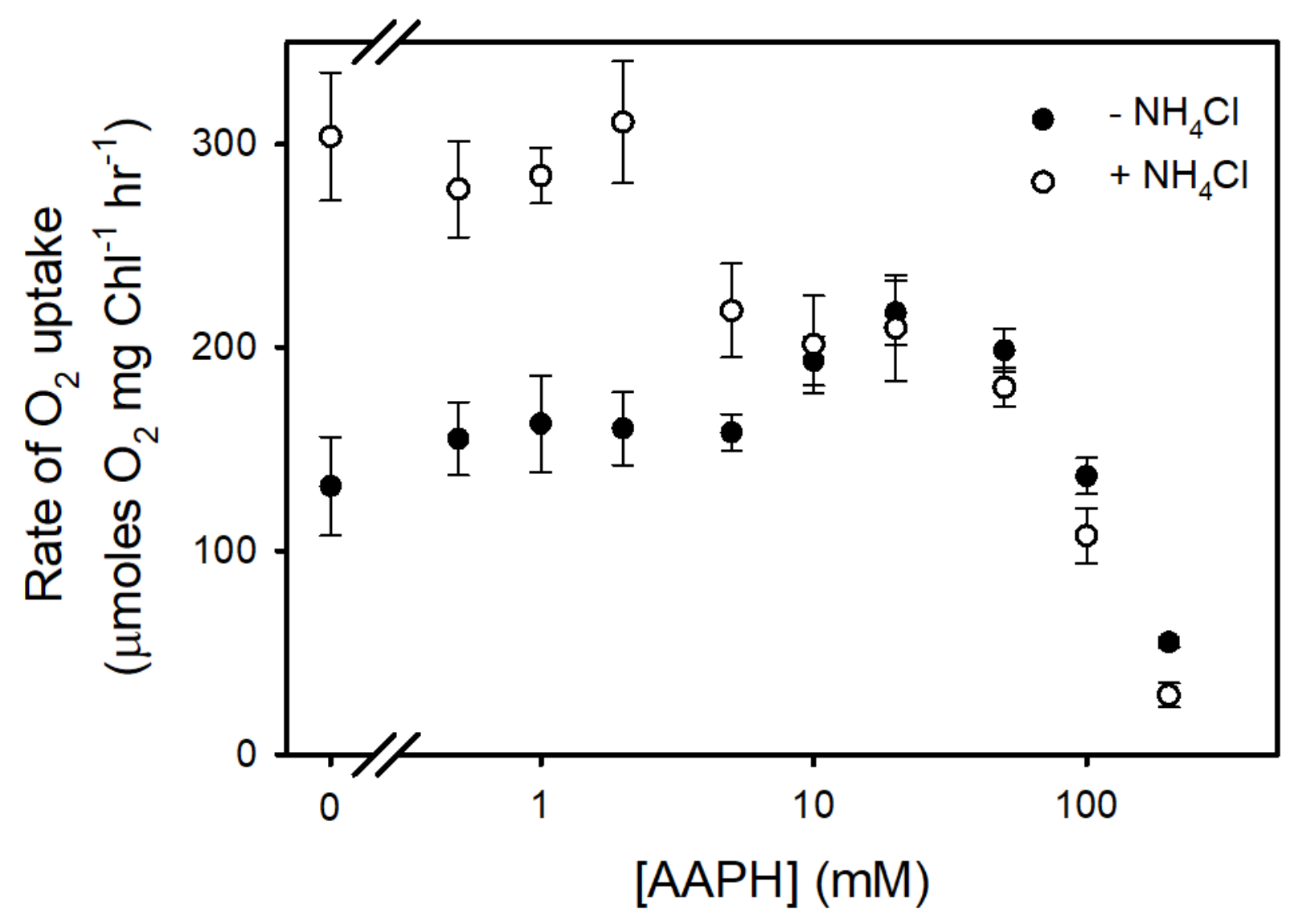

Figure 5 


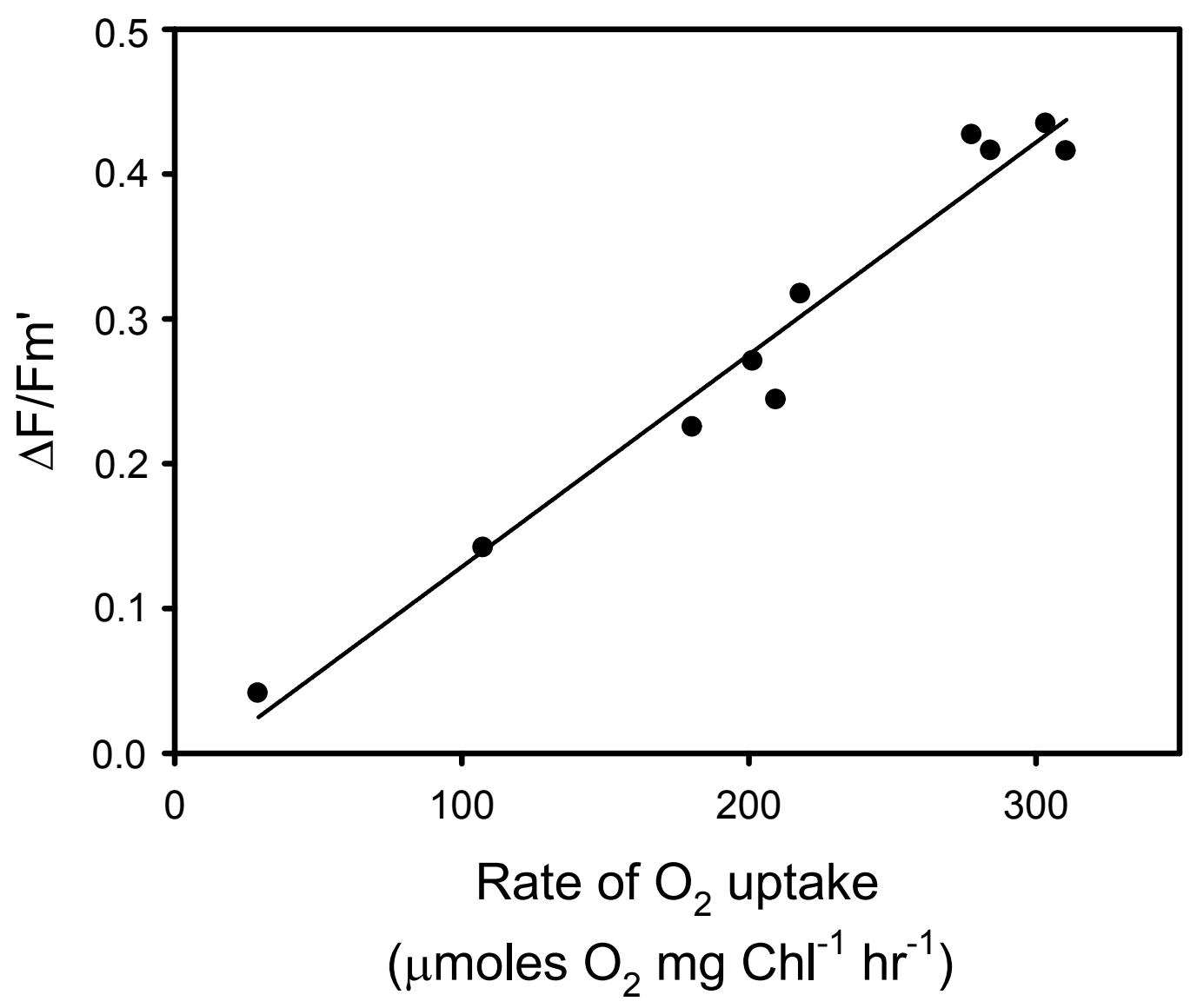

Figure 6 